\title{
GIST as a Lead Point in Adult Intussusception: Study in a Tertiary Hospital
}

\author{
Akther SMQ ${ }^{1}$, Reza SM${ }^{2}$, Hoque MM³, Mamun MAA ${ }^{4}$, Ahmed FU ${ }^{5}$, Khan RK ${ }^{6}$, Ahmed N ${ }^{7}$, Marium SN
}

\begin{abstract}
Conflict of Interest: None

Received: 05.08 .2019

Accepted: 15.10 .2019

www.banglajol.info/index.php/JSSMC

Introduction: Intussusception is very common in childhood between the ages of 5 months to 1 year. In adults it is a rarity, in whom it commonly presents with a nonspecific, repeated, chronic or subacute intestinal obstruction. Ninety percent of them have a variable number of secondary pathological 'lead point'- from benign lesion to malignant. ${ }^{5}$
\end{abstract}

Key Words:

Adult Intussusception, Pathological lead point, Adult Bowel obstruction, GIST,
Objective: This study aims to find out the variations \& the commonest 'Lead points' in rare adult intussusceptions.

Methodology: Study period was from January 2015 to June 2019. All patients of adult intussusceptions, admitted in Shaheed Suhrawardy Medical college Hospital, were examined, investigated, \& analysed peri-operative findings with post-operative histopathological results, in this prospective observational study.

Result: In this study, among 15 patients, GIST found to be the commonest (46\%) Lead point in adult intussusceptions. Others include Adenocarcinoma, Leiomyomatous polyp, Meckel's Diverticulum, intestinal TB, etc. Male was mostly sufferer (67\%). Ileoileal (II) variety was found more in male \& Ileocecal (IC) variety in female.

[J Shaheed Suhrawardy Med Coll 2019; 11(2): 138-141] DOI: https://doi.org/10.3329/jssmc.v11i2.48966

\section{Introduction}

Intussusception is defined as the "telescoping" or invagination of the proximal bowel wall into the adjacent distal segment, often causing bowel obstruction. It was first reported by Barbette ${ }^{1}$ of Amsterdam in 1674. A detailed report was further presented by John Hunter in 1789. ${ }^{2}$ Sir Jonathan Hutchinson ${ }^{3}$ was the first to operate on a child with intussusception in 1871 .

1. Dr. SM Quamrul Akther, Associate Professor, Dept. Of Surgery, ShSMC, Dhaka.

2. Dr. Syed Masud Reza, Associate Professor, Dept. of Surgery, ShSMC, Dhaka.

3. Dr. Md. Mozammel Hoque, Associate Professor, Dept. of Surgery, ShSMC, Dhaka.

4. Dr. Mohammad Abdullah-Al-Mamun, Associate Professor, Dept. of Surgery, ShSMC, Dhaka.

5. Dr. Farhad Uddin Ahmed, Assistant Professor, Dept. of Surgery, ShSMC, Dhaka.

6. Dr. Rafiul Karim Khan, Assistant Professor, Dept. of Surgery, ShSMC, Dhaka.

7. Dr Nadim Ahmed, Senior Consultant, Dept. of Surgery, ShSMCH, Dhaka.

8. Dr. Syeda Nishat Marium, HMO, Dept. of Surgery, ShSMCH, Dhaka.

Correspondence to: Dr. SM Quamrul Akther, Associate Professor \& Unit Head, Dept. of Surgery, ShSMC, Dhaka. Phone no: 01711059879 ,

E-mail:qa_sanju@yahoo.com
Intussusception is a very common disease of children, with a peak incidence between 5 months to 1 year of age, 90\% of all cases being idiopathic. However, in adults it is an extremely rare condition, representing about $5 \%$ of all cases of intussusception, and about $1 \%-5 \%$ cases of intestinal obstruction in adults. ${ }^{4}$

Almost $90 \%$ cases of intussusception are secondary to a pathologic condition that serves as a "lead point", such as carcinoma, polyps, Meckel's diverticulum, strictures or benign neoplasms. Most often these pathologic conditions are identified intra-operatively. ${ }^{5-7}$ There may be a risk of malignancy in almost $65 \%$ of the cases of intussusception, ${ }^{8,9}$ so definitive surgical treatment by surgical resection is usually the treatment of choice in almost $70-90 \%$ of the cases. ${ }^{10}$

Gastrointestinal stromal tumours (GISTs) are rare tumours of the GI tract, making up $0.2-1 \%$ of gastrointestinal malignancies ${ }^{18}$ First identified by Mazur and Clark in $1983^{19}$, these mesenchymal tumours can occur anywhere along the gastrointestinal tract. ${ }^{18,20}$ Relative rarity combined with non-specific presentation results in delayed diagnosis. ${ }^{21,22}$ 


\section{Objectives}

The purpose of this article is to present a prospective study of a total of 15 patients aged $\geq 18$ years, who were diagnosed with intussusception and treated in the department of Surgery of Shaheed Suhrawardy Medical College and Hospital, to highlight the variations and also to find out the commonest pathological 'lead points' which led to the development of intussusception in adults.

\section{Methodology}

The study period was from January 2015 to June 2019 . All patients aged $\geq 18$ years with intussusception were included. A detailed history was obtained from each patient, regarding symptoms: onset, duration, intensity, progression, etc, and a complete and thorough physical examination was done, in order to assess the condition of the patient and come to a clinical diagnosis. Further evaluation was done through diagnostic investigations, which include $\mathrm{CBC}$, ultrasonogram of the whole abdomen, plain X-ray of the abdomen in erect posture, colonoscopy and, in selected cases, CT-scan of the whole abdomen. Per-operative diagnosis was further confirmed by histopathology of the resected specimen.

\section{Result}

A total of 15 patients were finally diagnosed with adult intussusception. The relation of the age, sex and pathological lead points are shown in the diagrams and tables below:

In our study, Male patients were affected more 10(67\%) than Female patients 5 (33\%). Figure 1

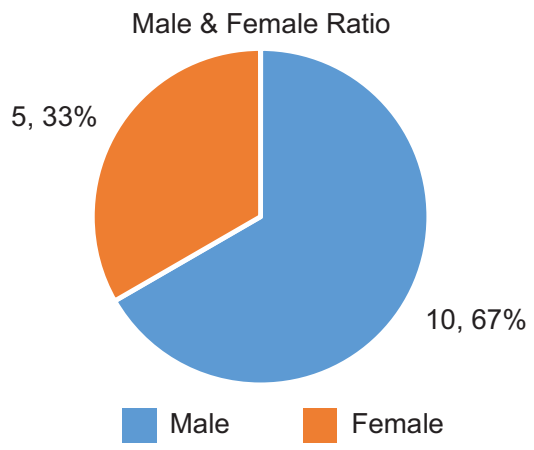

Fig.-1: Number of patients according to distribution of sex

This study shows that Gastrointestinal stromal tumours 'GIST' found to be the highest in frequency (7 patients) as 'pathological lead point' for adult intussusception, where 3 were female and 4 males. The second most leading cause was adenocarcinoma (3 patients), which mainly affected the males. Other causes included Leiyomyomatous polyp, Meckel's diverticulum, intestinal tuberculosis and lipoma (Table - I).
Table- I

\begin{tabular}{|c|c|c|c|}
\hline \multicolumn{4}{|c|}{$\begin{array}{c}\text { Number of patients affected by each underlying } \\
\text { pathological lead point }\end{array}$} \\
\hline Pathological & \multirow{2}{*}{\multicolumn{2}{|c|}{$\frac{\text { No. of patients affected }}{\text { Male }(\mathrm{n}) \text { Female }(\mathrm{n})}$}} & \multirow{3}{*}{$\begin{array}{r}\begin{array}{r}\text { Total } \\
\mathrm{n}(\%)\end{array} \\
7(46)\end{array}$} \\
\hline Lead point & & & \\
\hline$\overline{\text { GIST }}$ & 4 & 3 & \\
\hline Adenocarcinoma & 3 & 0 & $3(20)$ \\
\hline Leiyomyomatous polyp & 1 & 1 & $2(13)$ \\
\hline Meckel's diverticulum & 1 & 0 & $1(7)$ \\
\hline Intestinal TB & 1 & 0 & $1(7)$ \\
\hline Lipoma & 0 & 1 & $1(7)$ \\
\hline Total & 10 & 5 & $\overline{15(100)}$ \\
\hline
\end{tabular}

The most common form of intussusception found was the Ileo-ileal variety, affecting a total of $7(46 \%)$ patients, seen with almost every form of pathological lead point. Ileo-caecal variety was seen in only 5(33\%) patients, almost all of whom were diagnosed with GIST. The colocolic variety was found in adenocarcinoma and lipoma.

\section{Table-II}

\begin{tabular}{|c|c|c|c|c|}
\hline \multicolumn{5}{|c|}{$\begin{array}{l}\text { Types of intussusception and their underlying } \\
\text { pathology }\end{array}$} \\
\hline Pathological Lead Point & II & IC & $\mathrm{CC}$ & Total \\
\hline GIST & 3 & 4 & & 7 \\
\hline Adenocarcinoma & 1 & & 2 & 3 \\
\hline Meckel's Diverticulum & 1 & & & 1 \\
\hline Lipoma & & & 1 & 1 \\
\hline Intestinal TB & 1 & & & 1 \\
\hline Leiyomyomatous polyp & 1 & 1 & & 2 \\
\hline Total & 7 & 5 & 3 & 15 \\
\hline
\end{tabular}

$\mathrm{I}=$ ileo-ileal, $\mathrm{IC}=$ Ileo-colic, $\mathrm{CC}=$ colo-colic

Male patients presented with predominantly ileo-ileal variety (6 patients) while female patients presented with predominantly ileo-colic (3 patients) variety (Figure 2 ).

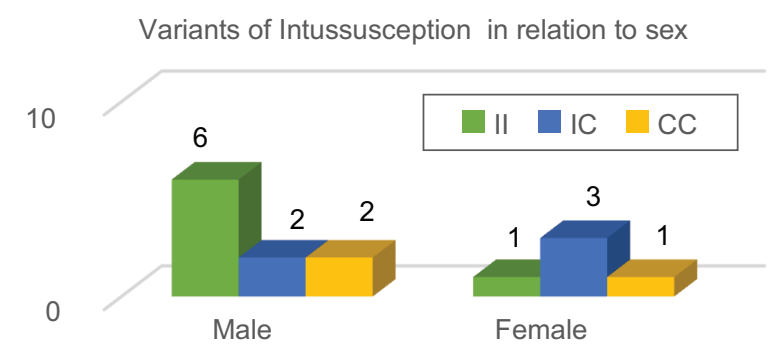

Fig.-2: Variants of intussusception in relation to sex 
The benign lesions were detected in almost $10(67 \%)$ of the cases, whereas $5(33 \%)$ of the cases were of malignant origin (Table -3$)$.

\section{Table-III}

\begin{tabular}{|c|c|c|}
\hline \multicolumn{3}{|c|}{$\begin{array}{c}\text { Relation of the number of intussusceptions with the } \\
\text { nature of the lesion }\end{array}$} \\
\hline & Benign & Malignant \\
\hline GIST (CD 117+) & & 2 \\
\hline GIST (CD 117-) & 5 & \\
\hline Adenocarcinoma & & 3 \\
\hline Meckel's diverticulum & 1 & \\
\hline Intestinal TB & 1 & \\
\hline Lipoma & 1 & \\
\hline Leiyomyomatous polyp & 2 & \\
\hline Total & 10 & 5 \\
\hline
\end{tabular}

\section{Discussion}

Adult intussusception is very rare. Intussusception is idiopathic in only about $8-20 \%$ of the adult cases and is more likely to occur in the small intestine., ${ }^{4,10,11}$ The remaining $90 \%$ is usually seen to initiate secondary to any pathological lesion of the bowel wall or irritant within the lumen that alters normal peristaltic activity and serves as a lead point, which is able to initiate an invagination of one segment of bowel into the other. ${ }^{10,12}$ This usually leads to obstruction of the free passage of the intestinal contents and, when severe, compromise of the vascular flow of the intussuscipient, thereby, causing inflammatory changes, ranging from thickening to ischemia of the bowel wall.

In the small intestine, an intussusception can be secondary to the presence of intra- or extra-luminal lesions (inflammatory, Meckel's diverticulum, post-operative adhesions, lipoma, adenomatous polyp, lymphoma and metastases) or iatrogenic (presence of intestinal tubes). ${ }^{13}$ Malignancy is found in up to $30 \%$ of the cases. ${ }^{10}$ In the Large intestine up to $66 \%$ of the cases are of malignant origin. ${ }^{10,12,14}$

The classic (pediatric) presentation of a triad of cramping abdominal pain, bloody diarrhoea and palpable tender mass, is extremely rare in adults. Often the presenting symptoms are non-specific, such as, nausea, vomiting, gastrointestinal bleeding, alteration of bowel habits, constipation or abdominal distension, and the majority of the cases in adults usually present with sub-acute or chronic, often repeated episodes of intestinal obstruction. ${ }^{4,15}$ A thorough physical examination usually, but not invariably, reveals a tender sausage shaped mass with concavity towards the umbilicus.
Investigations aimed at diagnosing adult intussusception include imaging studies, such as X-ray abdomen: plain $\mathrm{X}$-rays help to establish intestinal obstruction with the absence of caecal gas shadow in ileo-colic cases; Barium enemas usually reveal the claw-sign in the ileo-colic variety, but not useful in ileo-ileal variety. Ultrasonogram is more sensitive in children, revealing the doughnut appearance of the concentric rings in transverse section. The most accurate $(58-100 \%)$ imaging technique is the computerised tomography (CT) scan of the abdomen, which usually reveals a 'target' or 'sausage' shaped soft tissue mass ${ }^{[16]}$. However, most cases are often missed and usually diagnosed intra-operatively. ${ }^{5-7}$

Gastrointestinal stromal tumors (GISTs) are a subset of mesenchymal tumors of varying differentiation. They are rare clinical entities, constitute less than $3 \%$ of all gastrointestinal malignant neoplasms and represent only $20 \%$ of small-bowel malignant neoplasms. ${ }^{18}$ Classically GISTs grow exophytically, into the peritoneal cavity or adjacent organs ${ }^{22}$, further decreasing their likelihood of causing an intussusception. Rarely, however, GISTs can grow as a pedunculated polyp which may go on to act as a lead point for an intussusception. ${ }^{20}$ Their growth pattern leads to a range of non-specific symptoms (much like an intussusception), meaning GISTs often remain unnoticed until advanced enough to cause complications such as ulceration, obstruction or GI bleed. ${ }^{18}$

Prior to the introduction of imatinib, surgery was the only treatment available and to this day offers the only chance of cure ${ }^{23}$. Surgery is offered for all tumours over $2 \mathrm{~cm}$ in diameter, along with a role in debulking or symptomatic relief. ${ }^{24}$ Below $2 \mathrm{~cm}$ the natural history of these rare tumours is relatively unknown; therefore, treatment planning is difficult. Segmental resection should be performed rather than a peritumoral approach. Given the rarity of spread to lymph nodes, regional lymphadenectomy has not been found to be useful ${ }^{24}$. Adjuvant treatment with imatinib following surgical resection of GIST tumours can significantly reduce the risk of disease recurrence ( $6 \%$ recurrence on imatinib vs. $17 \%$ without therapy at 12 months).

\section{Conclusion}

GISTs are a subset of mesenchymal tumours and represent the most common mesenchymal neoplasms of Gastrointestinal tract. The clinical presentation of GIST is erratic. Furthermore, only $70 \%$ of the patients are symptomatic, while $20 \%$ are asymptomatic and $10 \%$ are detected at autopsy. The symptoms and signs are not disease - specific and as a consequence, about $50 \%$ of GISTs have already metastases at the time of diagnosis. 
Only up to $20 \%$ of all cases present with complete bowel obstruction and acute onset.

Adult intussusception is an extremely rare condition and usually presents with vague non-specific, sub-acute symptoms or intestinal obstruction.

In this study, Out of 15 cases 7cases of GIST was found as lead point of adult intussusception, so in our study GIST can be recognized as a "leading pathological lead point" of adult intussusceptions.

Nevertheless, a large scale multicentric study is necessary to conclude the inference.

\section{References}

1. de Moulin D. Paul Barbette, M.D.: a seventeenth-century Amsterdam author of best-selling textbooks. Bull Hist Med 1985; 59: 506-514

2. Noble I. Master surgeon: John Hunter. New York: J.Messner, 1971: 185

3. Hutchinson H, Hutchinson J. Jonathan Hutchinson, life and letters. 1st ed. London: Wm Heinemann Medical Books, 1946

4. Azar T, Berger DL. Adult intussusception. Ann Surg1997;226: $134-138$

5. Weilbaecher D, Bolin JA, Hearn D, Ogden W 2nd. Intussusception in adults. Review of 160 cases. Am J Surg1971; 121: 531-535

6. Stubenbord WT, Thorbjarnarson B. Intussusception in adults. Ann Surg 1970; 172: 306-310

7. Akcay MN, Polat M, Cadirci M, Gencer B. Tumor-induced ileoileal invagination in adults. Am Surg1994; 60: 980-981

8. Nagorney DM, Sarr MG, McIlrath DC. Surgical management of intussusception in the adult. Ann Surg 1981; 193: 230-236

9. Haas EM, Etter EL, Ellis S, Taylor TV. Adult intussusception. Am J Surg2003; 186: 75-76

10. Begos DG, Sandor A, Modlin IM. The diagnosis and management of adult intussusception. Am J Surg 1997; 173:88-94

11. Erkan N, Haciyanli M, Yildirim M, Sayhan H, Vardar E, Polat AF. Intussusception in adults: an unusual and challenging condition for surgeons. Int J Colorectal Dis 2005; 20: 452-456

12. Takeuchi K, Tsuzuki Y, Ando T, Sekihara M, Hara T, Kori T, Kuwano $\mathrm{H}$. The diagnosis and treatment of adult intussusception. J ClinGastroenterol2003; 36: 18-21
13. Ishii M, Teramoto S, Yakabe M, Yamamato H, Yamaguchi Y, Hanaoka Y, Ouchi Y. Small intestinal intussusceptions caused by percutaneous endoscopic jejunostomy tube placement. $J$ Am GeriatrSoc2007; 55: 2093-2094

14. Eisen LK, Cunningham JD, Aufses AH Jr. Intussusception in adults: institutional review. J Am CollSurg 1999; 188: 390-395

15. Martin-Lorenzo JG, Torralba-Martinez A, Liron-Ruiz R, FloresPastor B, Miguel-Perello J, Aguilar-Jimenez J, Aguayo-Albasini JL. Intestinal invagination in adults: preoperative diagnosis and management. Int J Colorectal Dis2004; 19:68-72

16. Williams NS, Bulstrode CJK, O'Connell PR. Bailey and Love's short practice of surgery; 26:1183-1194

17. Marinis A, Yiallourou A, Samanides L, Dafnios N, AnastasopoulosG, Vassiliou I, Theodosopoulos T. Intussusception of the bowel in adults: A review. World J Gastroenterol2009; 15(4): 407-411 Available from: URL: http://www.wjgnet.com/ 1007-9327/15/407.asp DOI:http://dx.doi.org/10.3748/ wjg. 15.407

18. Zakaria AH, Daradkeh S. Jejunojejunal intussusception induced by a gastrointestinal stromal tumour. Case Rep Surg. 2012;2022:173680. [PMC free article] [PubMed]

19. Mazur MT, Clark HB. Gastric stromal tumours. Reappraisal of histogenesis. Am J Surg Pathol. 1983;7:507-19. [PubMed]

20. Gupta A, Gupta S, Tandon A, Kotru M, Kumar S. Gastrointestinal stromal tumour causing ileo-ileal intussusception in an adult patient a rare presentation with a review of the literature. Pan Afr Med J. 2011;8:29. [PMC free article] [PubMed]

21. Martis JJS, Rajeshwara KV, Murulya KS, Raghavendra BK, Alex $\mathrm{KM}$. A rare case of jejunojejunal intussusception in an adult. Indian J Surg. 2013;75(Suppl 1):18-20. [PMC free article] [PubMed]

22. Vasiliadis K, Kogopoulos E, Katsamakas M, Karamitsos E, Tsalikidis C, Pringos B, et al. Ileoileal intussuception induced by a gastrointestinal stromal tumour. World J Surg Oncol. 2008;6:133. [PMC free article] [PubMed]

23. Siam FA, Siow SL. Stomach gastrointestinal stromal tumour (GIST) intussuscepted into duodenum: a case report. Malays J Med Sci. 2008;15:68-70. [PMC free article] [PubMed]

24. Casali PG, Blay JY. Gastrointestinal stromal tumours: ESMO Clinical Practise Guidelines for diagnosis, treatment and follow up. Ann Oncol. 2010;21:98-102. [PubMed] 